\title{
As cartas de leitores e leitoras enviadas a jornais impressos: o que querem informar os assinantes do jornal Estado de Minas
}

\section{Patrícia Espírito Santo}

Jornalista.Mestre em Ciência da Informação pela Escola de Ciência da Informação da Universidade Federal de Minas Gerais. Doutora em em Ciência da Informação pela Escola de Ciência da Informação da Universidade Federal de Minas Gerais

Lígia Maria Moreira Dumont

\begin{abstract}
Graduada em Biblioteconomia pela Universidade Federal de Minas Gerais. Graduada em Letras pela Universidade Federal de Minas Gerais.Mestre em Biblioteconomia pela Universidade Federal de Minas Gerais.Doutora em Ciência da Informação pela Universidade Federal do Rio de Janeiro em convênio com o IBICT. Professora titular e diretora de Cooperação Institucional da Reitoria da Universidade Federal de Minas Gerais.PósDoutora pela École de Hautes Études em Sciences Sociales, Paris
\end{abstract}

http://dx.doi.org/10.1590/1981-5344/1931

Ao considerar os meios de comunicação como mediadores de informações, além de produtores e reprodutores de padrões culturais e sociais, procurou-se identificar o que leitores/as escrevem aos jornais e como problematizam as temáticas abordadas em suas páginas; se haveria diferenças nos argumentos utilizados por cada gênero; e que argumentos utilizam para chamar a atenção dos/as editores/as e de seus/suas futuros/as leitores/as. Para tanto, coletou-se cartas enviadas em caráter espontâneo, por e-mail, ao jornal Estado de Minas, no período de 30 dias, e separou-se o material por temática; foi feita a análise do discurso de 60 cartas na íntegra, o que tornou possível conhecer a que valores recorrem leitores e leitoras, sobre quais hierarquias fundam os valores e em que lugares situam suas argumentações. Os resultados permitem concluir que os homens assinam quase $80 \%$ das cartas enviadas ao jornal, porém os valores, hierarquias e lugares apresentados nas cartas de ambos 
os sexos reproduzem a formação ideológica e discursiva de cada indivíduo, muito mais que denunciam a que gênero pertence. A análise do que informam as cartas de leitores/as de jornais impressos foi desenvolvida sob a ótica da Ciência da Informação.

Palavras-chave: Jornais e cartas leitores; Leitor e editor de jornais - opiniões; Gênero e informação jornalística.

\section{Letters from readers sent to newspapers: what subscribers of the newspaper Estado de Minas want to inform}

Analyzes what kind of information is contained in letters sent to printed media by readers of both sexes in the light of Information Sciences. In considering communication media information mediators, besides producing and reproducing cultural and social standards, the study attempted to identify what the readers, both male and female, write to newspapers and how they discuss the topics presented on their pages; and whether there would be any differences in the argumentation used by each gender; and also what argumentation the printed media uses in order to draw the attention of their current readers and also their prospect readers. Letters spontaneously sent by e-mail to Estado de Minas newspaper were collected during 30 consecutive days and sorted out according to topics and issues. An analysis of the discourse was carried out of 60 letters sent Estado de Minas which made it possible to learn the values the readers resort to, on which hierarchy levels they found their values and in which locations they place their argumentation. Results found have led to the conclusion that men sign almost $80 \%$ of letters sent to both papers. However, the values, hierarchies and locations presented in the letters of both genders reproduce the ideological and discursive background of each individual person more than they do the gender of the sender.

Keywords: Newspapers and reader's letters; Reader's and editors newspaper's opinions; Gender and newspaper information. 


\section{Introdução}

Diariamente, as mídias noticiosas recebem sugestões, comentários, críticas de todo tipo enviados por seus leitores e leitoras que, de certa forma, desejam intervir na produção da informação jornalística. Muitos deles são publicados, porém a maior parte é descartada, principalmente quando se trata dos veículos impressos, que têm mais limite de espaço que os eletrônicos. O fato de a maioria deles não ser aproveitada, impede que se torne pública uma enorme gama de informações sobre a forma como leitores/as veem o mundo, seus pontos de vista e como interpretam o que é discutido nas páginas de seus jornais favoritos.

Conhecer mais a fundo o universo constituído pelos textos enviados por leitores/as a jornais impressos foi o propósito deste trabalho. Para tanto, escolheu-se estudar os textos enviados por eles/as à editoria de Opinião do jornal Estado de Minas, líder de vendas em Minas Gerais entre os diários de referência ${ }^{1}$. O material enviado via e-mail foi aqui denominado carta, pois é dessa forma designado na redação dos jornais.

As cartas são dispositivos de enunciação que revelam os valores de quem as assina. Por isso, optou-se por realizar uma análise do discurso dos textos na tentativa de se conhecer quais valores essas informações transmitem e o que esses valores informam sobre a sociedade, visto que esse tipo de análise "não se interessa pela 'verdadeira' posição ideológica do enunciador real, mas pelas visões de mundo dos enunciadores inscritos no discurso" (FIORIN, 2006, p. 51).

As questões colocadas foram: haveria diferenças nos argumentos utilizados pelos homens em relação aos utilizados pelas mulheres nas cartas dos leitores e leitoras e quais utilizam para chamar a atenção dos/as editores/as e de seus futuros/as leitores/as? Vale destacar que tanto leitores quanto leitoras não demonstram muito interesse em enviar cartas às redações de jornais impressos (ESPÍRITO SANTO, 2007) e que é enorme a diferença entre o número de cartas assinadas por homens e por mulheres.

Através das cartas, pode-se conhecer as principais estratégias retóricas empregadas na elaboração do discurso argumentativo escrito pelo gênero masculino e pelo feminino, os argumentos aos quais homens e mulheres recorrem para dar sentido aos seus textos, persuadir, buscar credibilidade e criar proximidade com o jornal e seu público leitor. A exposição dos fatos, os juízos de valor e os tipos de argumentos utilizados por cada gênero foram alguns tópicos investigados nas missivas.

\footnotetext{
${ }^{1}$ Tétu (2002, p. 194) denomina jornal de referência àquele que, "impondo a priori um quadro para a percepção de tudo o que ocorre, produz um 'efeito de real'; indica explicitamente, para cada informação, a referência que o constitui como informação". É o caso de jornais que tentam produzir ou manifestar uma referência, ao contrário da imprensa popular, na qual o que prevalece é o acontecimento, o efeito de real e não seu significado. Tentam produzir ou manifestar uma referência, ao contrário da imprensa popular, na qual o que prevalece é o acontecimento, o efeito de real e não o seu significado.
} 
Não é recente a descoberta do fato nem novidade a escrita pública ser uma prática mais masculina que feminina. Sabe-se, com base nas ideias de Lahire (1997) e Fabre (1997), que o fato de as mulheres buscarem a publicação de opiniões em menor escala que os homens pode ter tido sua origem na forma como meninos e meninas eram (e ainda são) educados para os diversos tipos de escrita, primeiramente no seio de suas famílias, depois pela escola e pela própria sociedade.

Um jornal é muito mais do que um mero transmissor de informações e notícias, "é também um ponto de passagem da vida de uma sociedade [...] é um dos momentos desse viver", como afirma França (1998, p. 17). $\mathrm{Na}$ visão da autora, para sobreviver, os diários precisam se alimentar da força emanada pela vida social e a ela também alimentam, ou seja, os jornais são parte dos elementos e instrumentos que fazem a vida cotidiana, são espaços nos quais se produz a sociedade e não apenas na qual ela se reproduz.

As cartas foram consideradas, então, como instrumentos de transmissão de informação sobre a vida em sociedade. Fazem parte de um processo discursivo e estão inseridas em condições sócio-históricas. Páginas e colunas específicas para sua publicação servem como espaços de denúncia, de confronto do político/social, de reivindicação, de desabafo, enfim, de exercício da cidadania. Há que se considerar, ainda, que aqueles que escrevem representam uma população muito mais ampla que se possa dimensionar, porque, no fundo, são uma espécie de portavoz das queixas e observações de tantos/as outros/as que, por algum motivo, não enviam suas opiniões aos jornais. Dessa forma, as cartas foram analisadas como produto de uma interação social que reflete o pensamento de um grupo que deseja se informar e se comunicar em determinado contexto social, histórico e ideológico.

As cartas refletem o modo como leitores e leitoras pensam o mundo, sua opinião diante de grandes temas da atualidade. Por meio delas, os jornais podem observar como influenciam a formação do modo de pensar de seus públicos. Seus textos contribuem, também, para revelar o miseen-scène que tanto o público leitor quanto os próprios jornais realizam, enquanto atores de um mundo discursivo inseridos no processo de produção, organização e transmissão da informação.

\section{Informação e comunicação}

Saracevic (1996), ao investigar as origens da Ciência da Informação, destaca suas relações com outras disciplinas, em especial com a Biblioteconomia, a Ciência da Computação, a Ciência Cognitiva e a Comunicação Social. "Percebe-se que a interdisciplinaridade da Ciência da Informação é reflexo da interdisciplinaridade de seu próprio objeto de investigação, uma vez que o conceito de informação perpassa por diversas áreas do conhecimento", pontuam, também, Lemos e Nassif (2011). Para Duarte (2009, p. 65), a informação pode ser descrita como um dos subprocessos do processo de comunicação, pois "de um lado o processo 
de representação, buscando comunicar o sentido, realizado pelo sujeito comunicante; de outro lado, o processo de atribuição de sentido efetuado pelo sujeito interpretante".

A informação transmitida pelas palavras do público de jornais impressos foi, na pesquisa, tratada como um produto resultante do processo da comunicação entre leitores/as e veículos. Recorrer à linguística e aos princípios da Análise do Discurso, também tem trazido ganhos à área. González de Gómez (2004) chama a atenção para as relações que se faz entre a linguagem, a comunicação e a informação. A linguagem é vista como dimensão dos dispositivos de tratamento da informação e como dimensão das práticas e ações de informação dos sujeitos, das organizações e de outros estudos da significação.

Comunicar pressupõe o manejo de informações, o domínio da linguagem e o acesso aos conteúdos, o que permite produzir e difundir mensagens que contenham algum tipo de valor. Dessa forma, a questão da informação está estritamente ligada à questão da linguagem, o que volta o interesse ao estudo dos discursos que a envolvem.

A pesquisa partiu de dois pressupostos. Toda informação é social, é o primeiro. Qualificar a informação como social, para Cardoso (1994, p. 107-108), está longe de delimitar um campo de estudo. "Acaba por ampliá-lo, na medida em que podemos considerar como 'social' qualquer processo de produção/organização/consumo de informação, uma vez que ele acontece entre grupos, segmentos, classes". A informação foi considerada, antes de tudo, como um fenômeno que ocorre no âmbito da sociedade e das relações sociais.

O segundo pressuposto é que, nas cartas de leitores/as, não são as matérias ou o jornal que são discutidos, mas, diretamente, a situação em sociedade. Conforme enfatiza Braga (2006), a relação jornal-leitor, estabelecida através das cartas - entre produtores e usuários do produto - constrói (ou deveria construir) uma dependência mútua entre eles. "Essa relação [...] depende largamente de como cada uma das partes 'constrói' a outra, das expectativas e das reivindicações segundo as quais atribui papéis ao interlocutor" (BRAGA, 2006, p. 290).

Por isso, pensou-se a informação como ação dos sujeitos no mundo, em comunhão com outros sujeitos, que juntos articulam a compreensão de um mundo compartilhado. Para Araújo (2010, p. 97), situar a informação como sendo social é entendê-la como uma construção conjunta, coletiva, que tem relevância em determinado momento e para determinado grupo. "O que é informação não é produto de uma mente única, isolada, mas construída pela intervenção dos vários sujeitos e pelo campo de interações resultante de suas diversas práticas". Essa ideia é também compartilhada por Aquino (2007), para quem a informação só tem sentido quando concebida como prática e interações entre sujeitos, quando pensada como uma ação dos sujeitos no mundo.

A transferência de informação se coloca como um processo de troca de mensagens que tem um valor e não pode ser vista como isenta de ideologia (ARAÚJO, 1995). Ao se informar, o sujeito mescla o que já sabe 
com o que acaba de entrar em contato, o que altera ou não seu conhecimento e, por isto, acredita-se que o estudo da escrita - a partir da análise de correspondências enviadas aos jornais - auxilia na compreensão das experiências compartilhadas socialmente, as quais também se referem Capurro e Hjørland (2007). Através desse compartilhamento, é possível detectar, em parte, como se dá o processo de transformação do conhecimento, assim como a seleção e a interpretação da informação jornalística. Afinal "somos conformados por consensos coletivos, os quais também não se impõem mecanicamente sobre nós - pois somos nós que os construímos" (ARAÚJO, 2010, p. 27).

Segundo Dumont (2002), ao entrar em contato com um texto, o sujeito Ihe atribui significados que correspondem às informações que ele possui do mundo e dependem de seu estoque simbólico. Dessa forma, os jornais diários não devem ser vistos como meros transportadores de informações; eles auxiliam a criá-las e validá-las. Como toda mídia, para atender à demanda social de informação, os jornais contribuem na estruturação e na formação de grupos de interesses comuns e identidades compartilhadas, promovendo uma espécie de reflexibilidade na sociedade.

O jornal se configura, ainda, como um elemento com poder de vincular seus leitores e leitoras a outros lugares e, também, de funcionar como uma forma de comunicação entre eles. É pública a opinião que ele estampa, conforme assinala Chartier (2001), e essa opinião é que define um espaço abstrato da circulação do escrito entre pessoas que se unem, que não participam da mesma sociedade, mas que, em particular, ao ler ou escrever em sua esfera privada, se comunicam entre si, por meio da circulação do impresso. É um meio dialógico, mesmo que registre certo desequilíbrio entre as vozes que o constroem.

Apesar de Braga (2002) afirmar que, na prática, o espaço de publicação de cartas não acolhe debates relevantes e significativos, muito menos serve como efetivo controle da imprensa ${ }^{2}$, seu estudo pode dar uma ideia sobre os usos feitos pelo/a leitor/a desse tipo de canal de interação. Para o autor, mais que demonstrar a eficácia direta e imediata do controle dos jornais, o estudo das cartas de leitores auxilia na percepção das lógicas do processo, "assim como sua potencialidade de fornecer aos usuários (à sociedade, portanto) um instrumento críticointerpretativo que possa ampliar sua competência de 'leitura', de escolha, de 'edição'" (BRAGA, 2002, p.135). Para o autor, a carta funciona como uma resposta do leitor ao jornal.

\section{Sobre o Estado de Minas}

Segundo o site ${ }^{3}$ do Estado de Minas, o público de jornal é composto por $53 \%$ de leitores e $47 \%$ de leitoras, sem contar as

\footnotetext{
2 Essa foi a conclusão de Braga (2002), a partir de pesquisas realizadas por diversos autores, em colunas de correspondências feitas na Inglaterra, desde o século XVIII até 1977, e de suas próprias pesquisas realizadas em jornais brasileiros.

3 Disponível em: <www.diariosassociados.com.br/home/veiculos.php?co veiculo=29>. Acesso em: 2 out. 2011, época do início da pesquisa.
} 
assinaturas de pessoas jurídicas. A tiragem do jornal é de 73 mil exemplares nos dias úteis, subindo para 119 mil aos domingos, sendo que, só na Grande $\mathrm{BH}$, ele é lido por 531 mil pessoas, considerando a leitura compartilhada dos exemplares vendidos avulsos, em bancas e assinaturas. Circula em 702 municípios de Minas e cerca de 2\% dos exemplares são enviados para outras localidades do Brasil. Isso, talvez, explique o fato de o jornal adotar o slogan "O grande jornal dos mineiros".

Esses dados confirmam a percepção de França (1998), que o Estado de Minas mantém uma coerência na construção de sua identidade, fundada principalmente no enraizamento territorial, permeada pelo sentimento do mineiro. "Com relação à política editorial do cotidiano, já na sua fundação houve a preocupação de marcar a identidade de um jornal mineiro, comprometido com os interesses do Estado" (FRANÇA, 1998, p. 108).

São esses interesses, inclusive, que mais levantam suspeitas sobre a imparcialidade do jornal. São muitos, entre leitores/as, estudiosos/as e diversas lideranças, os/as que acusam o Estado de Minas de manter com os grupos do poder, principalmente os políticos que se revezam no governo do Estado e empresas que respondem por uma grande parte de sua receita de anúncios, uma relação de troca de favores (FRANÇA, 1998; 2002; CARRATO, 2002).

\section{Metodologia}

Para o desenvolvimento da pesquisa de campo, foram seguidas as seguintes etapas:

a)leta de todas as cartas na íntegra, recebidas via e-mail pela coluna Cartas à Redação ${ }^{4}$, do Estado de Minas, entre os dias 09 de fevereiro e 10 de março de 2009;

b)amostra de 30 dias consecutivos foi escolhida, tendo em vista que os jornais, de maneira geral, fazem suas programações editoriais dentro desse prazo. O total de cartas recebidas pelo Estado de Minas foi de 377 . Porém, a análise levou em consideração 348 cartas, pois foram descartadas as assinadas por assessorias de imprensa, por não expressarem a opinião da pessoa que as assina, mas, sim, da instituição que representam. Também não foram consideradas as cartas assinadas por pessoas cujos nomes ou textos foram insuficientes para identificar o sexo, assim como aquelas que traziam assinatura de homens e mulheres em conjunto. Outras cartas foram enviadas repetidas vezes;

\footnotetext{
${ }^{4}$ Optou-se por manter o nome da coluna como era designada quando da coleta das cartas. Em 15 de janeiro de 2012, ela passou a se chamar Espaço do leitor e a publicar também comentários feitos no mundo virtual sobre os assuntos abordados pelo Estado de Minas.
} 
c)pararam-se as cartas enviadas por temáticas, com objetivo de perceber quais temas e subtemas mais motivam leitores e leitoras a enviar cartas. Os nomes das temáticas coincidem com os nomes dos editoriais, pois é dessa forma que os jornais organizam seus cadernos e páginas e o/a leitor/a organiza sua leitura;

d)cartas foram separadas por temáticas/editorias presentes no jornal e, dentro de cada temática, foi feita uma subdivisão, agrupando as cartas cujo tema central tratava de um mesmo assunto ou subtema. Temáticas: Política/Nacional; Cidades; Internacional, Economia, Esportes e Ciência/Tecnologia. O objetivo, neste item, foi perceber quais temas e subtemas são mais discutidos pelas cartas; e

e)posse das cartas agrupadas por temas e por sexo, separaram-se aquelas que tratavam de um mesmo fato ou assunto para a realização da análise, comparando o discurso dos leitores com o discurso das leitoras. Realizou-se a análise do discurso de 60 cartas sendo:

1)14 sobre um aborto autorizado pela justiça brasileira, cujos envolvidos (equipe médica e família) receberam ameaça de excomunhão por parte da Igreja Católica. O padrasto violentou a enteada de nove anos, sendo que o bispo de Olinda disse considerar o aborto pior que o estupro. Dez cartas foram enviadas por leitores e quatro por leitoras;

2)15 sobre um escândalo de corrupção, envolvendo juízes do Tribunal de Contas do Estado, sendo 11 enviadas por leitores e quatro por leitoras;

3)22 sobre problemas registrados em Belo Horizonte, sendo 14 enviadas por leitores e oito por leitoras; e

4)nove relatos de problemas de atendimento social e política pública, sendo seis assinadas por mulheres e cinco por homens.

Outros assuntos tiveram repercussão na coluna, porém, a diferença encontrada entre o número de cartas enviadas por homens e o número enviado por mulheres sobre determinados fatos inviabilizou a análise de seus discursos e sua consequente comparação entre os gêneros ${ }^{5}$.

Dentre as teorias que servem como base para analisar discursos, optou-se por recorrer à nova retórica Perelmen e Olbrechts-Tyteca (2005), que procura caracterizar as diversas estruturas argumentativas. As premissas da argumentação não são evidentes, mas resultam de um acordo entre quem argumenta, no caso os/as leitores/as, e seu auditório,

\footnotetext{
${ }^{5}$ Exemplos em que a discrepância era maior no caso do Estado de Minas:

a) maus tratos a animal, seis cartas femininas e nenhuma masculina; e

b) justiça, quatro masculinas e nenhuma feminina.
} 
ou seja, os/as editores/as das seções de cartas e os próprios/as leitores/as dessas colunas. A forma como leitores/as sustentam suas argumentações diz um pouco sobre os elementos de expressão de si, como disse Fiorin (2006), seus valores, suas percepções do mundo, como eles e elas nele se apresentam. Auxiliou, também, a perceber como o/a leitor/a problematizaram as temáticas publicadas nos dois jornais.

Foi possível perceber até que ponto leitores/as acreditam nas versões dos fatos dados pelo jornal e como julgam os sujeitos das matérias e artigos. Os valores são, também, objetos de acordos, aos quais se recorre quando se estrutura uma argumentação. Foram considerados, neste trabalho, como sendo um dos mais importantes meios de auxiliar na compreensão da forma como cada gênero pensa temas polêmicos, sempre tão explorados pela mídia e com grande repercussão entre o público leitor de jornais.

Perelman e Olbrechts-Tyteca (2005, p. 89) chamam a atenção para o fato de quando um discurso sente necessidade de se basear principalmente em valores, demonstra certo desejo de mudança. Os valores "podem servir comodamente para a crítica por não levarem em consideração pessoas e parecerem fornecer critérios a quem quer modificar a ordem estabelecida".

Ao recorrer a valores, o grupo fundamenta hierarquias que informam sobre suas preferências. Para Perelman e Olbrechts-Tyteca (2005, p. 94), o que caracteriza cada grupo é principalmente o modo como ele hierarquiza os valores. A retórica descrita pelos autores trata, ainda, dos lugares comuns, nos quais se fundamentam valores e hierarquias. Eles citam, como exemplos gerais, os lugares da quantidade, da qualidade, da ordem, entre outros.

Os valores dão espaço à discussão, podem ser contestados, desqualificados, interpretados, ou seja, seu aspecto não universal permite conceder-Ihes um estatuto particular. Porém, ao expor valores através de suas palavras, o/a leitor/a sabe que corre o risco de não ter a adesão do/a leitor/a da coluna, que pode ter outros valores e objetar suas ideias.

Reconhece-se que analisar um discurso é presumir o que seu autor quis dizer e presumir, também, como seu público o interpretou. Ao fazer a análise das cartas, não se pretendeu dar conta de tudo o que faz o ponto de vista dos/as leitores/as, muito menos do ponto de vista do jornal e do público leitor das cartas.

\section{As conclusões}

A análise do discurso aplicada na interpretação do conteúdo das cartas levou às interpretações que mais se destacaram na pesquisa.

A primeira pergunta: o que será que eles e elas realmente escrevem ao jornal, o que desejam informar através de suas cartas? Teve-se, como percepção, que foram as temáticas que mais motivaram os leitores/as a escrever aos jornais. Nesse ponto, não foram encontradas diferenças entre a predileção de leitores e a de leitoras. A editoria de 
Política/Nacional foi a que mais recebeu cartas de ambos os sexos, aproximadamente $54 \%$ do total de enviadas, seguida pela editoria de Cidades, com aproximadamente 31\%, e Economia, com aproximadamente $7 \%$. Nesse ponto, é importante observar que, apesar de o Estado de Minas ter construído sua identidade fundada no "enraizamento territorial" (FRANÇA, 1998), foram principalmente fatos ocorridos fora dos limites de Minas Gerais e acontecimentos políticos locais, com reflexos nos destinos da nação, que mais motivaram leitores/as a dar sua opinião. Sobre Política/Nacional, eles enviaram 154 cartas e elas 33.

O leitorado do Estado de Minas tende a fazer da coluna Cartas à Redação um espaço de publicação de sua opinião sobre os fatos e não um local aberto para críticas e polêmicas em torno do tratamento que o jornal dá aos temas. Entre as cartas enviadas no período pesquisado, apenas uma diz ter encontrado uma informação equivocada, nenhuma se preocupou em corrigir possíveis erros gramaticais e, também, apenas uma leitora criticou a abertura que o jornal deu a uma carta preconceituosa em relação aos hemofílicos. Em contrapartida, pouco mais de 5\%, sendo $78 \%$ deles leitores, elogiaram a forma como o jornal se posiciona frente aos fatos e às notícias.

Percebe-se, também, que a maioria dos/as leitores/as não citou o nome do jornal ou de outros órgãos de imprensa como fonte de informação sobre os fatos tratados em suas cartas. Pode-se concluir que eles e elas não acreditam ser importante ancorar seus argumentos no discurso midiático, pois pressupõem que qualquer leitor/a das colunas saiba situar os acontecimentos tematizados em suas páginas.

Pode-se afirmar, então, com base no que disseram Perelman e Olbrechts-Tyteca (2005), que a presunção de credulidade natural, que faz com que o primeiro movimento seja o de acreditar naquilo que nos é dito, foi observada entre o leitorado do Estado de Minas. Este fato indica que é grande a confiança que os/as leitores/as têm em relação ao jornal, assim como uma postura menos crítica e polêmica junto à forma como o diário aborda os fatos em suas páginas.

Observou-se, também, que nem sempre os subtemas mais discutidos em suas páginas são os que mais recebem cartas. A dengue, por exemplo, foi tema de 14 matérias e, apesar de ser um problema que ameaçava a saúde pública, não motivou leitores/as e leitoras a enviar sua opinião, sendo que apenas uma carta masculina o abordou.

Os homens escrevem mais para os jornais; assinaram $79 \%$ das cartas enviadas ao Estado de Minas. Consequentemente, foram eles também que dominaram o espaço da coluna: $78 \%$ das cartas publicadas. As mulheres são $47 \%$ do público leitor do jornal. Acredita-se que parte dessa discrepância, entre a leitura e a escrita feminina para o jornal, seja reflexo principalmente de dois fatores. Algumas teorias (LAHIRE, 1997) buscam explicar porque as mulheres se interessam mais por escrever do que os homens, principalmente durante a infância e a adolescência, tendência que se inverte quando eles e elas se veem diante da necessidade de redigir cartas administrativas e profissionais na vida 
adulta. Os meninos são educados para escrever mais com a razão do que com a emoção, enquanto a sociedade valoriza a escrita doméstica como sendo uma atribuição do feminino. O segundo fator diz respeito ao que expôs o editor de opinião do Estado de Minas, Pedro Lobato (em conversa informal): as mulheres não se interessam em ter os refletores voltados para si, no que diz respeito ao espaço do leitor, tanto quanto os homens. $\mathrm{E}$ o fato de eles terem escrito mais cartas que elas, inclusive sobre os subtemas que Ihes afetam diretamente, como aborto, denuncia a maior indisponibilidade delas para discutir o que quer que seja através de cartas a jornais.

Eles, inclusive, tendem a escrever textos mais longos que elas, estendem as discussões por mais tempo. Eles e elas, sem dúvida, são atentos à forma como a sociedade é tratada por ela mesma e pelas autoridades. Leitores/as se revoltaram com a corrupção no Tribunal de Contas do Estado, com o descaso em relação aos aposentados, com o julgamento da igreja em relação ao estupro e ao aborto, com a falta de atenção aos problemas da cidade de Belo Horizonte, entre outros. Porém, a maioria evitou colocar o presidente e o governador no centro das discussões políticas, o que parece indicar que o leitorado do jornal evita fazer críticas diretas a eles, porque provavelmente acredita que elas não serão publicadas, ou os que escrevem ao jornal estão tão afinados com a política editorial do jornal que concordam com o tratamento dado às notícias sobre o governo.

Por outro lado, nem os/as leitores/as nem a coluna pouparam críticas à administração municipal, apesar de, na época, as relações entre o jornal e a prefeitura foram acusadas de tendenciosas por autores como França (1998), Carrato (2002) e Vasconcelos (2006). As cartas evitaram fazer críticas diretas aos governantes. Fizeram-nas à estrutura administrativa, transferindo, assim, a responsabilidade da busca de soluções aos subordinados dos chefes do executivo e até mesmo ao povo de Belo Horizonte e do restante do Estado. Tanto o Estado de Minas quanto seu leitorado, depositam o problema no cargo e não na pessoa que o ocupa.

Para os/as leitores/as que enviam cartas, deixar clara sua ocupação também não se mostrou prática frequente. Entre os/as autores/as das 60 cartas do Estado de Minas que tiveram seus discursos analisados, apenas seis citaram sua profissão, sendo quatro leitores e duas leitoras. Isso indica que recorrer ao posto social que ocupam não está entre as principais estratégias utilizadas, tanto por leitores quanto por leitoras, para valorizar suas ideias e buscar reconhecimento como alguém a quem o/a editor/a e, consequentemente, o/a futuro/a leitor/a, devam dar credibilidade. Ou, ainda, apesar de a profissão/ocupação ser socialmente vista como um lugar de fala, ou, ainda, um lugar social do discurso, eles e elas preferiram falar como cidadãos e cidadãs, o que dispensa credenciais. A própria coluna Cartas à Redação habitualmente não publica a ocupação dos/as autores/as. No final das cartas publicadas, consta apenas o nome completo de quem as escreveu e a cidade/região onde moram. 
Porém, percebeu-se que o Estado de Minas tem o hábito de utilizar, nos títulos que cria, substantivos que identificam seus/suas autores/as socialmente como professora, aposentado, delegado, leitor, mineiro, entre outros. Acredita-se que termos como esses, que aparecem em 39 dos 154, tenham a função principal de dar uma identidade à opinião professada, tirando das costas do jornal o peso da posição que ela assume. As autoridades foram minoria entre os que escreveram, o que comprova que elas não encaram as seções de cartas como espaços a explorar a seu favor. No entanto, quando enviaram cartas, foi o próprio jornal que os identificou como autoridades. Viu-se isso acontecer através da publicação da carta assinada por uma ex-secretária municipal de educação. O texto original não trazia a função por ela ocupada.

Isso leva também ao resgate da tese de função-autor de Foucault (1992). Os/as leitores/as que enviam cartas parecem mais interessados em emitir uma opinião, como forma de contribuir para um debate de temas que consideram relevantes, do que em serem reconhecidos como autores/as de novas ideias e perspectivas de análise dos fatos. Com base na visão foucaultiana, as seções cartas não se configuram como espaço adequado ao exercício da autoria. Quem escreve uma carta e a envia à redação, não sendo um autor assim descrito, poderia ser classificado como um redator. Conclui-se, então, que qualquer um pode escrever e enviar uma carta às redações dos jornais e sua publicação não está condicionada ao seu status perante o público do jornal. São, em sua maioria, pessoas comuns, cujos nomes próprios não identificam sua função social, nem as qualificam como alguém a quem se deva dar uma atenção especial.

Dessa forma, o gênero sexual é uma categoria que leva em conta a análise dos hábitos e costumes mantidos por sociedades e culturas, pois interferem nas relações dando-lhes sentido e organizando os papéis que cabem a cada sexo. Porém, em geral e na sociedade ocidental, é tido que esses papéis são cada vez menos rígidos e determinados. Porém, a análise demonstra, ainda, essa divisão de forma bem clara.

Segunda pergunta: que argumentos os/as autores/as das cartas utilizam para chamar a atenção dos/as editores/as e de seus futuros/as leitores/as; haveria diferenças nos argumentos utilizados pelos homens em relação aos utilizados pelas mulheres?

Apesar de algumas cartas redigidas por elas ainda trazerem resquícios de docilidade e de fragilidade, por muitos séculos atribuídas às mulheres, a realidade é outra. Notou-se que elas também são capazes de serem grosseiras e utilizar termos chulos, uma característica esperada muito mais por parte deles, ao contrário deles que criticaram personalidades sem recorrer a termos considerados de baixo calão. O fato de os elogios aos jornais terem partido principalmente deles, também comprova essa alternância de papéis.

As cartas na íntegra fizeram da cidadania sua palavra-chave, um valor fundado em uma hierarquia, ao posicionar as leis civis acima dos fatos, sendo essas mesmas hierarquias incompatíveis em certas situações. 
Para leitores/as do Estado de Minas, o valor da vida é inquestionável, desde que ela não seja oriunda de um estupro de uma menor pelo padrasto. A cidadania pode não aparecer explicitamente na maioria dos textos, mas a ética que a encerra esteve muito presente.

No entanto, não foram encontradas diferenças significativas entre os argumentos de leitores e de leitoras e conclui-se que a vivência no masculino e no feminino pouco influencia a forma como as pessoas hierarquizam os valores. Os valores que se apresentaram nas cartas de opinião reproduziram a formação ideológica e discursiva da pessoa, muito mais que denunciaram a que gênero elas pertenciam. Seria mais correto dizer que os valores aos quais leitores/as do jornal recorreram os/as dividem em grupos que têm as mesmas preferências, independentemente do gênero ao qual pertencem.

Um ponto semelhante foi quanto à pessoa do verbo. Em sua maioria, leitores e leitoras fizeram uso da primeira pessoa em suas cartas. Não apenas expuseram os fatos, mas se posicionaram como, de certa forma, estando com eles, neles e por eles envolvidos e, ao mesmo tempo, se credenciara como porta-vozes de grupos a quem deixaram perguntas - muitas vezes acompanhadas de suas respostas, convidando-os a entrar nas discussões. As perguntas que constam nas cartas deram espaço, mesmo que não explicitamente, a uma única resposta em concordância com a ideia de quem as formulou: todos/as compartilham da mesma opinião - "a minha".

Nas cartas que versavam sobre problemas na cidade de Belo Horizonte, eles/as recorreram principalmente a valores como direito e justiça, tradição de família e moralidade como necessários para a manutenção da cidadania. As cartas que abordaram problemas de atendimento social, enfrentados por leitores e leitoras, também recorreram principalmente a valores como direito, proteção e justiça, sendo que o lugar de qualidade recebeu destaque.

Nas cartas que repercutiram o escândalo no Tribunal de Contas do Estado, observou-se que a justiça esbarra em outro valor: a esperança ou a falta dela devido ao fato de que é o próprio governo, que a princípio deveria promover a justiça, está abrindo espaço à impunidade.

A cidadania surgiu nas cartas sobre o aborto e a excomunhão de outra forma. Tanto para leitores quanto para leitoras, sejam eles crentes ou não, ela só é compatível no Estado laico, que impede que as leis religiosas julguem os atos da sociedade civil. Eles e elas basearam suas argumentações na necessidade de separar dois valores: Estado e Igreja. Dessa forma, eles e elas acreditam que a evolução dos dois valores dependa da promoção da cidadania.

As cartas sobre aborto/excomunhão são um exemplo de como elas podem funcionar como medidores que estimam o grau de repercussão dos artigos e reportagens junto aos/às leitores/as. Elas começaram a ser enviadas apenas após um membro do clero ameaçar excomungar a equipe médica e a mãe da menina grávida. Não foi o estupro em si, tampouco o aborto, que causaram inquietação, tanto de leitores quanto 
de leitoras, mas seu desdobramento: a ingerência da Igreja em um assunto que cabe à sociedade civil julgar. Tanto que outros episódios de abortos e de violência sexual foram temas de 18 reportagens no Estado de Minas e não receberam uma única carta.

As cartas sobre problemas de atendimento social depositaram, também, na cidadania, a esperança de se alcançar uma solução. Seu exercício, do mesmo modo, está nas mãos primeiro do Estado e depois da mídia. Os jornais são vistos como instrumentos capazes de cobrar do Estado, assim como da própria sociedade, o cumprimento da ética cidadã. Por isso, cidadãos e cidadãs apelam aos espaços a eles/as concedidos em suas páginas.

Os/as leitores/as se alternaram quanto ao tomar para si a responsabilidade de dar novo rumo à sociedade. Enquanto a maioria deles/as se vê hierarquicamente abaixo das instâncias de poder, que falharam no cumprimento de seus deveres, alguns/mas poucos/as acreditam que o/a cidadão/ã também apresente condições de solucionar os problemas. No caso das cartas sobre Belo Horizonte, apenas leitores se viram como fatores de mudança, enquanto nas cartas sobre o TCE foram as leitoras que demonstraram acreditar que a sociedade deve se mobilizar para reverter a situação. Quando os problemas eram pessoais, os dois gêneros se posicionaram como impotentes.

Ao optar pela publicação das cartas enviadas que relatam questões pessoais, o Estado de Minas valoriza a "face positiva do/a leitor/a", abrindo-Ihe "concessões", parafraseando Maingueneau (2005). Ao mostrar interesse pelas necessidades de seu público, o jornal aceita suas reivindicações como legítimas. Outro exemplo dessa preocupação foi a publicação de uma errata, na qual o jornal reconheceu a omissão de uma informação que considerava importante ter constado em uma carta publicada: o nome da agência bancária alvo de uma denúncia.

A valorização do/a leitor/a pode ser vista também através da promoção de diálogos entre os/as leitores/as por parte do Estado de Minas. Percebe-se que 24 cartas, entre as 60 analisadas, trouxeram referências a outras cartas publicadas pela coluna, sendo que 18 foram publicadas. Dessa forma, a coluna quer passar a impressão de que dá ao/as leitores/as espaço para que discutam entre si pontos de vista sobre temas abordados pelo jornal, assim como sobre temas introduzidos pelos/as próprios/as leitores/as. Nos fóruns de discussões estabelecidos, percebeu-se uma disputa simbólica sobre qual interpretação dos fatos deveria prevalecer. Além disso, ao publicar sete cartas-respostas das assessorias de imprensa de empresas alvos de acusações por parte de leitores, o Estado de Minas se posicionou, também, como prestador de serviços, um intermediário na resolução de conflitos pessoais ou locais.

Afora as cartas sobre o aborto e a excomunhão, que apesar de condenarem a posição da Igreja, fundaram seus argumentos de forma diferente umas das outras. Alguns/as se declararam católicos/as, mas deixaram claro que, acima da religião, está a cidadania. Já outros/as, preferiram justificar sua posição através de explicações oriundas da 
biologia e da anatomia, ou ainda da moral e dos bons costumes. Outros/as transferiram o problema apenas para o bispo que propôs a excomunhão, isolando-o da igreja que ele representa. Tudo isso ilustra o drama interno de leitores e leitoras, quando o assunto em discussão diz respeito ao sistema de crenças, que traz consigo valores como a liberdade e os direitos individuais. Não houve dúvida entre colocar a lei civil acima da religiosa; mas houve "pecado" e sensação de culpa declarada ao fazêlo.

Já entre as cartas analisadas enviadas ao Estado de Minas, apenas as leitoras se preocuparam em defender a autonomia da mulher sobre seu corpo, na discussão sobre aborto/excomunhão. Esse ponto leva à reflexão de questões que dizem respeito ao feminino: elas são mais facilmente registradas e levadas em conta pelas mulheres do que pelos homens que enviara cartas ao jornal.

Entre os lugares, os da quantidade foram os menos explorados, sendo que tanto leitores quanto leitoras não viram, em números e estatísticas, a melhor base para desenvolver seus argumentos.

Concluiu-se que quem se aventura a escrever a um jornal impresso não se esquiva de preencher uma "página em branco", que se configura como a tela do computador, na qual produz sentido sobre algo que deseja convidar ao debate. Expõe ideias, as defende, fala de suas indignações, de suas surpresas, daquilo que chama sua atenção. Ao construir seu texto, o carrega de valores, expõe suas hierarquias e os lugares de onde fala, derrama sobre a tela uma série de símbolos, às vezes, sem um sentido muito claro aos olhos de quem os lê, mas, ao fazê-lo, traça ali um sistema. E, por último, crê estar cumprindo uma proposta: atuar como cidadão/ã. Faz do jornal impresso um lugar da sociabilidade, como preconizou Chartier (2001), quando nele busca informação, a processa na esfera privada, a refaz com suas próprias palavras carregando-a de valores, palavras que deseja ver publicadas, comentadas, sem fugir do risco de vê-las sendo desprezadas ou contestadas. Assim, ao escrever a jornais, leitores e leitoras se inserem no processo de circularidade da informação e contribuem com a produção de notícias.

Para finalizar, não se pode deixar de assinalar que novas tendências sobre a escrita se configuram através do crescente desenvolvimento das tecnologias da informação. É cada vez maior o número de pessoas, principalmente entre as mais jovens, que se interligam, sem se verem pessoalmente; que se conhecem, sem nunca terem se encontrado; que se falam através de palavras, símbolos, imagens, estando cada uma em um ponto distinto do mundo ou até mesmo bem ao lado; que chamam de "amigos" centenas de milhares de indivíduos. Para elas, a escrita, vista como a impressão de informações sobre uma "tela em branco", é o instrumento de comunicação que permite uma maior circularidade da informação. As redes sociais abrem tantas possibilidades de comunicação que fica difícil prever até quando o papel, oriundo do velho pergaminho, irá resistir, qual será seu papel no futuro, assim como até quando o hábito de imprimir as notícias no que foi sabiamente batizado como papel-jornal 
persistirá. Mas não se pode negar que o foi construído pelos e nos diários imprimiu, e vem imprimindo, a história das sociedades.

\section{Referências}

AQUINO, M. de A. A ciência da informação: novos rumos sociais para um pensar reconstrutivo no mundo contemporâneo. Ciência da informação, Brasília, v. 36, n. 3, p. 9-16, set./dez. 2007.

ARAÚjO, V. M. R. H. de. Sistemas de informação: nova abordagem teórico-conceitual. Ciência da Informação, Brasília, v. 24, n. 1, p. 54/76, jan./abril 1995.

ARAÚJO, C. A. Á. Estudos de usuários conforme o paradigma social da ciência da informação: desafios teóricos e práticos de pesquisa. Inf. Inf., Londrina, v. 15, n. 2, p. 23-39, jul./dez. 2010.

BRAGA, J. L. O sistema social crítico interpretativo. In: PRADO, J. L. A. (Org.). Crítica das práticas midiáticas. São Paulo: Hacker Editores, 2002. p. 27-43.

BRAGA, J. L. A sociedade enfrenta sua mídia. São Paulo: Paulus, 2006.

CAPURRO, R.; HJØRLAND, B. O conceito de informação. Perspectivas em Ciência da Informação, Belo Horizonte, v. 12, n. 1, p. 148-207, jan./abr. 2007.

CARDOSO, A. M. P. Retomando possibilidades conceituais: uma contribuição à sistematização do campo da Informação Social. Revista da Escola de Biblioteconomia da UFMG, Belo Horizonte, v. 23, n. 2, p. 107114, jul./dez. 1994.

CARRATO, Â. Imprensa mineira: um monopólio próximo do fim. In: MOUILLAUD, M.; PORTO, S. D. (Orgs.). O jornal: da forma ao sentido. Brasília: Ed. Universidade de Brasília, 2002. p. 469-481.

CHARTIER, R. Cultura escrita, literatura e história. Porto Alegre: Artmed, 2001.

DUARTE, A. B. S. Ciclo informacional: a informação e o processo de comunicação. Em Questão, Porto Alegre, v. 15, n. 1, p. 57 - 72, jan./jun. 2009.

DUMONT, L. M. M. Os múltiplos aspectos e interfaces da leitura. DataGramaZero - Revista de Ciência da Informação, Rio de Janeiro, v. 3, n. 6, dez. 2002.

ESPÍRITO SANTO, P. Leitura e interatividade feminina nos jornais impressos: a postura da leitora do Estado de Minas. 2007. 330f. Dissertação (Mestrado em Ciência da Informação) - Escola de Ciência as Informação, Universidade Federal de Minas Gerais, Belo Horizonte, 2007. 
FABRE, D. Seize terrains d'écriture. In: FABRE, D. (Org.). Par écrit: ethnologie des écrites quotidiennes. Paris: Maison des Sciences de I'Homme, 1997. p. 1-56.

FIORIN, J. L. Linguagem e ideologia. São Paulo: Ática, 2006.

FOUCAULT, M. A escrita de si. In: FOUCAULT, M. O que é um autor. Lisboa: Edições 70, 1992. p. 128-160.

FRANÇA, V. R. V. Jornalismo e vida social: a história amena de um jornal mineiro. Belo Horizonte: Editora UFMG, 1998.

GONZÁLEZ DE GÓMEZ, M. N. Novas fronteiras tecnológicas das ações de informação: questões e abordagens. Ciência da Informação, Brasília, v. 33, n. 1, p. 55-67, 2004.

LAHIRE, B. Masculin-féminin: I'écriture domestique. In: FABRE, D. (Org.). Par écrit: ethnologie des écrites quotidiennes. Paris: Maison des Sciences de l'Homme, 1997. p. 145-161.

LEMOS, A. B.; NASSIF, M. E. Informação e notícia: conexões no âmbito da Ciência da Informação e da Comunicação Social. DataGramaZero - Revista de Ciência da Informação, Rio de Janeiro, v. 12, n. 3, jun. 2011. Disponível em: <http://www.dgz.org.br/jun11/Art 03.htm>. Acesso em: 26 mar. 2012.

MAINGUENEAU, D. Análise de textos de comunicação. São Paulo: Cortez, 2005.

PERELMAN, C.; OLBRECHTS-TYTECA, L. Tratado da argumentação: a nova retórica. São Paulo: Martins Fontes, 2005.

SARACEVIC, T. Ciência da Informação: origem, evolução, relações. Perspectivas em Ciência da informação, Belo Horizonte, v. 1, n. 1, p. 4162, jan./jun. 1996.

VASCONCELOS, F. Aécio maquiou gastos da saúde em Minas. Folha de São Paulo, São Paulo, 13 ago. 2006. Caderno Brasil, p. 18. 